\title{
Software livre e software proprietário: elementos do debate entre liberais e comunitaristas na adi $n^{\circ} 3.059 / \mathrm{rs}^{*}$
}

\section{Free software and proprietary software: elements of the debate between liberals and communitarians in the adi $n^{\circ} 3.059 /$ rs}

\section{Resumo}

O objetivo do ensaio é identificar concepções de justiça em meio aos argumentos apresentados em ação submetida ao Supremo Tribunal Federal. A ação escolhida discute a constitucionalidade de lei do Estado do Rio Grande do Sul, que dá preferência ao software livre em suas licitações. A partir da comparação de teses selecionadas, busca-se identificar nesse caso elementos do debate norte-americano entre liberais e comunitaristas das décadas de 1980 e 1990.

Palavras-chave: Software livre. Software proprietário. Licitações. Liberalismo. Comunitarismo.

\begin{abstract}
The purpose of this essay is to identify conceptions of justice among the arguments presented in case submitted to the Federal Supreme Court of Brazil. The chosen case discusses the constitutionality of law from the State of Rio Grande do Sul which gives preference to free software in its biddings. From the comparison of selected thesis, I seek to identify in the case elements of the 1980s and 1990s American debate between liberals and communitarians.
\end{abstract}

Keywords: Free software. Proprietary software. Bidding. Liberalism. Communitarianism.

\footnotetext{
* Recebido em: abril de 2012. Aprovado em: abril de 2012.

1 Bacharel em Direito e Mestrando em Direito e Políticas Públicas pelo Centro Universitário de Brasília (UniCEUB), onde também participa do Programa de Estágio Docente. Advogado.
} 


\section{Introdução}

Neste ensaio, pretendo fazer uma análise da Ação Direta de Inconstitucionalidade (ADI) no 3.059/RS. Por meio dessa ação, foi submetida ao Supremo Tribunal Federal (STF) discussão a respeito da constitucionalidade de lei do Rio Grande do Sul que dá preferência - nas licitações feitas por aquele Estado - à aquisição de software livre. Meu objetivo é identificar as concepções de justiça que norteiam (ainda que implicitamente) os argumentos apresentados no processo. A abordagem que desejo fazer é, porém, limitada. Fiz um recorte no caso e elegi alguns participantes que defendem teses opostas, a fim de compará-las. Não é, portanto, uma análise de todo o conteúdo veiculado na ADI. Identificar concepções de justiça nos argumentos elaborados em um caso judicial pode parecer uma meta pretensiosa, e de fato o é. Para tornar minha tarefa um pouco mais palpável, redefino os termos do trabalho, a fim de melhor expressar o meu escopo. O que me proponho a fazer é apontar suposições defensáveis sobre as concepções de justiça que me parecem nortear alguns dos argumentos apresentados no caso.

Para orientar (e, com isso, delimitar) a investigação a respeito das concepções de justiça, utilizo uma discussão que é própria da filosofia política. Busco perceber, na comparação das teses selecionadas, elementos que se aproximam do famoso debate norte-americano entre liberais e comunitaristas. A princípio, a proposta me pareceu viável porque, mesmo antes de me debruçar sobre o caso, acreditei haver distintas concepções de justiça relacionadas a cada um dos pólos de interesse que (suponho) nele se opõem. De um lado, está a indústria do software proprietário, que almeja a declaração da inconstitucionalidade da lei, e, do outro, os defensores do software livre, que preferem ver a confirmação de sua constitucionalidade.

Em relação à indústria do software proprietário, pensei que fosse possível associar uma abordagem liberal, já que, mesmo em uma análise superficial, identifiquei referências a conceitos liberais (como a igualdade, por exemplo) nas peças que defendem a inconstitucionalidade da lei. Quanto aos defensores do software livre, minhas suposições se apoiavam em leituras prévias que havia feito a respeito do chamado movimento do software livre. Como alguns representantes desse movimento o apresentam como uma iniciativa eminentemente ética (que ressalta, por exemplo, as vantagens sociais que decorrem pudesse se pautar em ideias que mais se aproximariam de uma abordagem comunitarista. Com a expectativa de confirmar minhas intuições iniciais, voltei-me à leitura das peças e dos documentos que instruem o processo.

\section{A lei n० 11.871/2002 e a adi n० 3.059/rs}

No dia 18 de fevereiro de 2002, o deputado Elvino Bohn Gass apresentou à Assembleia Legislativa do Rio Grande do Sul o Projeto de Lei n ${ }^{\circ}$ 06/2002. Segundo sua ementa, o projeto dispõe sobre a utilização de programas de computador naquele Estado. O primeiro dos seis artigos que o compõem sintetiza o objeto da norma. De acordo com esse dispositivo, fica determinado que a administração pública do Estado do Rio Grande do Sul (em toda sua extensão) deverá utilizar “[...] preferencialmente em seus sistemas e equipamentos de informática programas abertos, livres de restrições proprietárias quanto a sua cessão, alteração e distribuição".2

No final daquele ano, mais precisamente em 19 de dezembro de 2002, o então Governador do Estado, Olívio Dutra, sancionou o Projeto de Lei, dando origem à Lei $\mathrm{n}^{\circ}$ 11.871. O projeto havia sido aprovado, no dia 4 de dezembro de 2002, pela Assembleia Legislativa, juntamente com uma emenda proposta pelos deputados Adilson Troca e Jorge Gobbi. Por meio da emenda, foi acrescentado mais um parágrafo ao artigo $1^{\circ}$. A redação do parágrafo indicava que a implantação da preferência determinada pela lei deveria ser "[...] feita de forma paulatina, baseada em estudos técnicos e de forma a não gerar perda de qualidade nos serviços prestados pelo Estado."3

Cerca de um ano depois, no dia 28 de novembro de 2003, o então Partido da Frente Liberal (PFL), hoje, Democratas (DEM), protocolou no Supremo Tribunal Federal (STF) petição em que sustenta a inconstitucionalidade da lei gaúcha. De acordo com o partido, “[...] antes que o setor público faça uma escolha, ainda mais por meio de lei, é necessária maior reflexão, tanto do ponto de vista fático, quanto jurídico". ${ }^{3}$ Assim, seguindo a tradição da redação forense, o partido organiza seus argumentos a partir de dois tópicos centrais: "dos fatos" e "do

2 RIO GRANDE DO SUL. Assembleia Legislativa. Projeto de Lei $n^{\circ} 06 / 2002$. p. 2.

3 Ibidem, p. 14.

${ }^{4}$ BRASIL. Supremo Tribunal Federal. ADI no 3.059/RS. p. 5. 
direito." No primeiro tópico, o partido transcreve a lei e faz observações a respeito do mercado de programas de computador, apresentando uma distinção entre software proprietário e software livre. No segundo tópico, o partido formula sua tese em termos estritamente jurídicos. Desenvolve quatro argumentos para fundamentar a inconstitucionalidade da lei.

Em primeiro lugar, a lei seria inconstitucional por versar sobre tema que somente poderia ser legislado pela União, a saber: normas gerais de licitação e contratação. Para o partido, outro motivo que levaria à inconstitucionalidade da lei é o fato de que ela estabelece preferência entre concorrentes, o que viola o princípio da impessoalidade. A próxima tese é moldada com base em outros dois princípios. Dessa vez, o partido afirma que preferências estabelecidas por lei não levam em conta as peculiaridades dos casos concretos, o que implicaria em "[...] clara afronta aos princípios da economicidade e da eficiência, pois é impossível determinar, genericamente, qual será o melhor produto ou serviço para todas as necessidades administrativas [...]". Por fim, a lei seria inconstitucional por vício de iniciativa. Isso porque apenas o Governador (e não a Assembleia Legislativa, como ocorreu no caso) poderia dar origem à lei impugnada, uma vez que leis que tratem de organização administrativa e matéria orçamentária são de sua iniciativa privativa.

Proposta a ação e ouvidos o Governador e a Assembleia Legislativa do Estado do Rio Grande do Sul, o STF decidiu conceder medida cautelar (também solicitada pelo partido), para suspender os efeitos da lei gaúcha até decisão definitiva a respeito de sua constitucionalidade. Após esse julgamento, deveriam ser ouvidos, de acordo com o que estabelece a legislação, o Governador, a Assembleia Legislativa do Estado, o Advogado Geral da União (AGU) e o Procurador-Geral da República (PGR). O Governador não se manifestou, a Assembleia Legislativa estadual reproduziu os argumentos que apresentou na sua intervenção anterior, enquanto o AGU e o PGR defenderam a constitucionalidade da lei. Até a data de conclusão deste ensaio, o processo ainda aguardava julgamento definitivo de seu mérito.

\section{Os amici curie}

Em 2006, três associações civis solicitaram a participação no processo e foram admitidas na condição de amici curie. Em primeiro lugar, no dia 27 de janeiro daquele ano, pediram a inclusão, em conjunto e representadas pelo mesmo escritório de advocacia, a Associação Brasileira das Empresas de Software (ABES) e a Associação das Empresas de Tecnologia da Informação, Software e Internet (ASSESPRO Nacional). Mais tarde, no dia 20 de setembro de 2006, foi a vez do Instituto Brasileiro de Política e Direito da Informática (IBDI). As duas primeiras associações pugnaram pela declaração de inconstitucionalidade da lei, enquanto o IBDI requereu o reconhecimento de sua constitucionalidade. Acredito que essas associações representam de uma maneira mais explícita (pelo menos em relação aos demais intervenientes) a defesa daqueles dois polos de interesse a que fiz referência no início do ensaio. Isso fica ainda mais evidente quando se examina os fundamentos que essas associações apresentam para justificar o seu ingresso no processo como amici curie (conferir abaixo). Por isso, dedico-me a elas neste trabalho.

\subsection{Representatividade das associações}

Para participar de uma ação direta de inconstitucionalidade na condição de amicus curie, é necessário que o órgão ou a entidade interessada atenda a dois requisitos (cf. art. $7^{\circ}, \S 2^{\circ}$, da Lei $\left.n^{\circ} 9.868 / 1999\right)$. O primeiro deles é que a matéria discutida seja relevante. Nesse ponto, não acredito que haja dificuldades para demonstrar o atendimento a esse pressuposto, já que a ADI no 3.059/RS lida com um assunto de interesse do Estado e tem significativa repercussão no mercado de software. Não me preocuparei com isso. O que me importa aqui é o segundo requisito. Segundo ele, o interessado deve ter representatividade.

A representatividade da ABES e da ASSESPRO Nacional está ligada diretamente aos interesses da indústria do software. Pelo menos, é assim que elas a fundamentam. Eis o que disseram:

[...] as Peticionárias são associações civis que congregam todo o universo de agentes produtores de tecnologia da informação empregada em meio eletrônico, contando com mais de 1.400 integrantes, que atuam em quase todos os Estados da Federação. ${ }^{6}$ 
E continuaram, mais à frente: "Indubitavelmente, as Peticionárias são das mais representativas da sociedade civil do setor que possuem interesse na presente demanda $[\ldots]^{\prime}{ }^{7}$

O IBDI justifica sua representatividade de modo diferente. Começa dizendo que: “[...] é uma associação civil sem fins lucrativos instituída na forma de organização social. Objetiva a pesquisa, o estudo e a divulgação de questões que guardam relações com o Direito e as Tecnologias da Informação e Comunicação". Após descrever suas atividades, conclui: “[...] espera-se que reste demonstrado, pela natureza e objetivos intrínsecos da entidade, ser nacionalmente representativa desta área do Direito, e de notória atuação prática sobre a matéria em discussão [...]". 9 Portanto, o IBDI não representa uma indústria do software livre, mas profissionais e acadêmicos da área jurídica. Considerando que o instituto foi admitido a atuar no processo, sua representatividade também foi reconhecida pelo tribunal. Esse é um aspecto interessante. Em primeiro lugar, porque a representatividade (enquanto termo jurídico) parece ser um conceito amplo. Em segundo lugar, porque não é possível afirmar que haja de fato uma indústria organizada de software livre; mesmo assim, porém, há pessoas organizadas que defendem a sua adoção.

\subsection{Selecionando os argumentos}

Antes de tratar detidamente dos argumentos das associações, cabe fazer uma última observação quanto aos contornos da minha abordagem. Ainda que as teses estritamente jurídicas sejam importantes, algumas delas não parecem servir aos propósitos que elegi para este trabalho. O problema do vício de iniciativa e a determinação do alcance da expressão "norma geral”, por exemplo, são assuntos fundamentalmente técnicos, que em nada contribuem para a avaliação de concepções de justiça. Ficam, por isso, desde já excluídos da minha análise. Quanto aos demais argumentos, acredito ser possível reorganizá-los

\footnotetext{
BRASIL. Supremo Tribunal Federal. ADI no 3.059/RS. p. 271.

8 Ibidem, p. 330.

9 Ibidem, p. 331.
}

a partir de três temas centrais: $:^{10}$ a) diferença entre software proprietário e livre; b) custos com o software; e, c) princípio da impessoalidade e tratamento igualitário dos concorrentes.

O primeiro deles traz em si uma questão terminológica. Embora a distinção que propõe seja apropriada, não me parece essencial para o desenvolvimento desta pesquisa discuti-la em profundidade. Farei referências pontuais quando for necessário. O segundo tema, por outro lado, permite que se faça uma comparação da maneira como as associações lidam com a avaliação dos custos com o software. Enquanto ABES e ASSESPRO Nacional tratam a questão do ponto de vista financeiro, o IBDI chama a atenção para outros tipos de vantagem que decorreriam da adoção do software livre. Seriam, basicamente, aspectos relacionados à segurança nacional, ao acesso à informação e à transferência de tecnologia. Esse tema me parece conter elementos interessantes para a averiguação

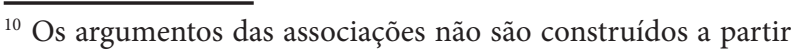
dos três aspectos que destaquei. A organização estrutural das peças dá pistas (ainda que de maneira limitada) dessa circunstância. ABES e ASSESPRO Nacional dividiram sua peça em seis tópicos: i) da possibilidade jurídica da presente manifestação; ii) da admissibilidade da presente manifestação; iii) dos fatos atinentes à demanda; iv) do direito; v) da conclusão; e, vi) dos pedidos. O tópico iv, por sua vez, foi subdividido em outros três: a) da violação do artigo 37, caput e inciso XXI, da Constituição Federal de 1988; b) da violação do artigo 22, inciso XXVII da Constituição Federal; c) da violação do princípio da separação dos poderes. O IBDI, por outro lado, dividiu sua peça em cinco tópicos: i) do cabimento da presente manifestação; ii) da representatividade do postulante; iii) da relevância da matéria; iv) dos fatos; e, v) do direito. Os dois últimos tópicos recebem outras subdivisões. O tópico iv é composto por: a) software livre versus software proprietário; b) da confusão entre proprietário e comercial; c) relevância estratégica do uso do software livre na administração pública; d) software é tecnologia de controle e de administração da informação; e, e) da estrita observância dos princípios constitucionais. O tópico v é subdividido em outros quatro: a) da suposta afronta ao art. 22, XXVII da CF; b) afronta do princípio da impessoalidade; c) da afronta ao princípio da eficiência e da economicidade; e, d) da suposta afronta à separação dos poderes e ao processo legislativo. A reorganização dos argumentos me pareceu uma iniciativa fundamental. Isso porque, da forma como estavam apresentados, os argumentos dificultavam a compreensão do debate, impedindo a investigação a respeito das concepções de justiça a eles subjacentes. Uma passagem de Wittgenstein, em particular, chamou-me a atenção para a tarefa: "A philosophical problem is a consciousness of the disorder in our concepts which can be removed by an ordering." WITTGENSTEIN, Ludwig. The nature of philosophy. In: KENNY, Anthony (Ed.). The Wittgenstein reader. 2. ed. Oxford: Blackwell Publishing Ltd., 2006. p. 54. Eis, portanto, a razão de tentar ordenar os conceitos aqui discutidos. 
das concepções de justiça a ele subjacentes. No entanto, deixo para examiná-lo em outra oportunidade, dedicando-me somente ao terceiro tema. Isso porque o debate acerca do princípio da impessoalidade envolve conceitos que, a meu ver, podem ser pensados sob a perspectiva da ideia de justiça procedimental, o que vai explicitamente ao encontro do debate norte-americano entre liberais e comunitaristas. Sigo, portanto, nesses termos.

\subsection{Princípio da impessoalidade e tratamento igualitário}

Dando prosseguimento à minha análise, examino a tese que é construída a partir do princípio da impessoalidade. De acordo com o que disseram a ABES e a ASSESPRO Nacional, o Estado deve agir de maneira impessoal em sua relação com os particulares, o que significa que lhe é vedado instituir privilégios e preferências entre eles. Demonstram, assim, que o princípio da impessoalidade decorre de outro princípio, o da igualdade, segundo o qual o Estado deve dispensar tratamento igualitário aos particulares. Aplicando essas noções aos contratos administrativos, as duas associações chegam à seguinte assertiva: “[...] a Administração Pública deve conferir trato isonômico a todos os seus eventuais fornecedores ou consumidores, inexistindo a possibilidade de quaisquer favorecimentos particulares" ${ }^{11}$ Prosseguindo com seu argumento, as associações afirmam que a licitação foi o instrumento eleito pela Constituição (art. 37, XXI) para dar efetividade ao princípio da impessoalidade. ${ }^{12} \mathrm{E}$ concluem dizendo que a Lei Estadual no 11.871/2002 violou a Constituição justamente porque desvirtuou o procedimento licitatório, prevendo privilégio que coloca os concorrentes em situação de desigualdade.

A resposta do IBDI segue dois caminhos. Por um lado, defende a preferência estipulada pela lei gaúcha e, por outro, acusa a utilização do software proprietário de violar o princípio da impessoalidade. A defesa da preferência é feita a partir da ideia de que a diferença entre software proprietário e livre diz respeito apenas à forma de licenciamento. Para o IBDI, “[a] classificação do software como livre ou proprietário não depende [...] do bem software em si, mas sim da amplitude com a qual os direitos de utilização daquele bem foram licenciados."13 Sendo as-

${ }^{11}$ BRASIL. Supremo Tribunal Federal. ADI no 3.059/RS. p. 279

12 Ibidem, p. 280

${ }^{13}$ Ibidem, p. 334 sim, a preferência por um tipo de licenciamento não seria fator que confere tratamento diferenciado aos concorrentes, já que todos eles poderiam optar por autorizar o uso livre e sem ônus de seu software. Portanto, o licenciamento (e a preferência por esse licenciamento) seria apenas um dentre vários critérios técnicos a serem avaliados em um certame licitatório, o que não violaria o princípio da impessoalidade. De acordo com o instituto: "[...] assim como o princípio da impessoalidade admite, em face das necessidades do licitante, critérios técnicos e econômicos para balizar a avaliação performativa dos softwares concorrentes [...], deveria pelas mesmas razões admitir, em face dos interesses da administração pública e do Estado, critérios técnicos - no sentido jurídico do termo - para balizar a avaliação performativa das licenças concorrentes [...]". ${ }^{14}$

Além dessa defesa, o IBDI contra-ataca, imputando a pecha de violação do princípio da impessoalidade ao uso do software proprietário. A tese é formulada no sentido de que o licenciamento proprietário cria situação de monopólio, ao dar ensejo à dependência tecnológica do Estado em relação ao detentor dos direitos autorais sobre o software. Os prejuízos à concorrência seriam sentidos, por exemplo, no que tange aos serviços para alteração do software, já que o licenciamento proprietário “[...] exige que quaisquer serviços dessa natureza sejam contratados junto ao fornecedor do software, caracterizando favorecimento de longo prazo a tal fornecedor [...]". ${ }^{15} \mathrm{E}$ é precisamente esse favorecimento que caracterizaria a violação do princípio da impessoalidade, já que o licenciante proprietário é colocado em posição mais privilegiada em relação aos demais concorrentes.

\section{As concepções de justiça}

Feita a exposição dos argumentos das associações, passo a examiná-los sob a perspectiva do debate norteamericano entre liberais e comunitaristas. Antes, porém, é necessário contextualizar o debate, ainda que brevemente, e, se possível, traçar as características gerais que diferenciam as teses em conflito. A primeira coisa a fazer é identificar o período em que o debate se desenrola. Refiro-me aqui às críticas e defesas liberais e comunitárias elaboradas durante as décadas de 1980 e 1990. O segundo elemen-

\footnotetext{
${ }^{14}$ BRASIL. Supremo Tribunal Federal. ADI no 3.059/RS. p. 348.

${ }^{15}$ Ibidem, p. 340.
} 
to a considerar já foi dito: é um debate norte-americano. Dessa constatação, um tanto quanto óbvia, decorre um aspecto de particular importância. A discussão é feita entre interlocutores que participam de uma tradição específica, diferente da nossa. Assim, as teorias que ali foram desenvolvidas não podem ser simplesmente importadas e aplicadas ao contexto brasileiro; é preciso fazer as adaptações necessárias, a fim de adequá-las à nossa própria tradição (ou, quem sabe, considerá-las incompatíveis com ela). Falta, por fim, explicar em que consiste o debate.

\subsection{O debate liberal-comunitário}

Para os propósitos deste trabalho, bastam noções gerais. Começo com referências ao liberalismo. Fundamental é saber que não existe um liberalismo, mas liberalismos. O liberalismo, quando assim nomeado, não é uma teoria unitária. Seria algo mais próximo a uma doutrina que, a partir de preocupações comuns, desenvolve-se em diversos sentidos e dá origem a variadas teorias. Dentre aqueles normalmente associados ao liberalismo, há autores clássicos como Thomas Hobbes, John Locke, Adam Smith e John Stuart Mill. No entanto, o liberalismo, ou melhor, os liberalismos que importam para este trabalho são aqueles desenvolvidos no século XX. E, ao falar de filosofia política contemporânea, é o nome de John Rawls que vem à tona, juntamente com o título de sua obra seminal, "Uma teoria da justiça." ${ }^{16}$ A preocupação principal de Rawls é, por assim dizer, “[...] explicar [e demonstrar a prioridade das] liberdades e direitos básicos dos cidadãos como pessoas livres e iguais". ${ }^{17}$ À explicação dessas liberdades e direitos básicos, normalmente é associada outra preocupação ao liberalismo político contemporâneo, a saber: a investigação do papel do Estado. Para Allen E. Buchanan, a tese liberal defende que [...] o papel adequado do Estado é proteger liberdades individuais básicas, não tornar seus cidadãos virtuosos ou impor a eles qualquer concepção particular ou substantiva da boa vida."18

${ }^{16}$ Há, por certo, outros liberais contemporâneos notáveis. Apenas para citar dois, indico como exemplos Ronald Dworkin e Thomas Nagel. De qualquer forma, é reconhecido o papel de destaque alcançado pela teoria da justiça de Rawls.

${ }^{17}$ RAWLS, John. Uma teoria da justiça. São Paulo: M. Fontes, 2000, p. 14.

${ }^{18}$ Tradução livre do original: "[...] the proper role of the state is to protect basic individual liberties, not to make its citizens virtuous or to impose upon them any particular or substantive conception of the good life." BUCHANAN, Allen E. Assessing the communitarian critique of liberalism. Ethics, Chicago, v. 99, n. 4, p. 854, 1989.
O debate começaria a tomar forma quando às ideias acima fossem contrastadas as críticas dos comunitaristas. No entanto, identificar em que consistem essas críticas não é nada fácil. Igualmente como ocorre com o liberalismo, não há apenas um comunitarismo. ${ }^{19}$ No caso das teorias comunitaristas contemporâneas, porém, o crédito é mais bem dividido, destacando-se nomes como, por exemplo, os de Michael Sandel, Alasdair MacIntyre, Michael Walzer e Charles Taylor. Acontece que a existência de diversos comunitarismos é percebida de maneira diferente em comparação ao que ocorre com os diversos liberalismos. No caso das críticas comunitárias, essa circunstância parece pesar negativamente. $\mathrm{O}$ comunitarismo chega, inclusive, a ser acusado de não compor um corpo teórico consistente.

A ilustrar essa situação, tomo Sandel como exemplo, destacando o que ele disse no prefácio que apresentou para a segunda edição de sua famosa obra, "Liberalismo e os limites da justiça”. Para Sandel, em determinadas ocasiões, o debate consiste na oposição "[...] entre aqueles que prezam a liberdade individual e aqueles que pensam que os valores da comunidade ou a vontade da maioria devem sempre prevalecer", ou, ainda, “[...] entre aqueles que acreditam em direitos humanos universais e aqueles que insistem que não há como criticar ou julgar os valores que informam diferentes culturas e tradições" ${ }^{20}$ Por negar a posição comunitária expressa nessas sentenças - posição a que chama de "majoritarista" - e reconhecer a existência, em meio ao debate, de temas variados, o autor afirma que nem sempre se encontra do lado comunitarista. ${ }^{21}$ Sandel diz que, para ele, a questão “[...] não é se os direitos são importantes, mas se os direitos podem ser identificados e justificados de uma forma que não pressupõe qualquer concepção particular de vida

${ }^{19}$ Buchanan chega a afirmar, inclusive, que " $\left.t \mathrm{t}\right]$ here are perhaps almost as many communitarian positions as there are communitarian writers." BUCHANAN, Allen E. Assessing the communitarian critique of liberalism. Ethics. Chicago, v. 99, n. 4,1989 , p. 852.

20 Tradução livre do original, que, completo, segue assim: “The debate is sometimes cast as an argument between those who prize individual liberty and those who think the values of the community or the will of the majority should always prevail, or between those who believe in universal human rights and those who insists there is no way to criticize or judge the values that inform different cultures and traditions." SANDEL, Michael. Liberalism and the limits of justice. 2. ed. Cambridge: Cambridge University Press, 1998, p. 9-10.

${ }^{21}$ SANDEL, Michael. Liberalism and the limits of justice. 2. ed. Cambridge: Cambridge University Press, 1998, p. 9. 
boa.". 22 Desse modo, mesmo Sandel, apontado como um dos principais representantes do comunitarismo, não se identifica completamente com essa doutrina.

Ainda que as observações de Sandel apontem a dificuldade em fazer generalizações a respeito das críticas comunitaristas, elas também servem como pistas a respeito do que dizem essas críticas. Essas pistas, contudo, não são suficientes. Busco mais subsídios em um texto liberal. Isso pode parecer curioso, mas para rebater as críticas comunitaristas é preciso identificá-las. Nesse sentido, utilizo a síntese feita por Buchanan. Segundo ele, seriam cinco os argumentos mais comuns dos trabalhos comunitários: a) o liberalismo ignora ou negligencia a comunidade; b) o liberalismo desvaloriza a vida política; c) o liberalismo não leva em conta alguns tipos de obrigação que não se originam de uma escolha ou manifestação de vontade, tais como as obrigações com a família ou com o país; d) o liberalismo parte de uma concepção equivocada da personalidade (o termo original seria "self", em inglês), ignorando que essa personalidade está imersa em uma dada comunidade e é por ela ao menos parcialmente constituída; e) o liberalismo entende, equivocadamente, que a justiça é a mais importante ou a primeira virtude social, quando, na verdade, esse papel de destaque seria da comunidade, e a justiça funcionaria apenas como um corretor. ${ }^{23}$ Esses seriam os contornos gerais dos argumentos comunitários.

${ }^{22}$ Tradução livre do original: "[...] is not whether rights are important but whether rights can be identified and justified in a way that does not presuppose any particular conception of good life." SANDEL, Michael. Liberalism and the limits of justice. 2. ed. Cambridge: Cambridge University Press, 1998, p. 10.

${ }^{23}$ Buchanan sintetiza as críticas comunitaristas nos seguintes termos: “i) Liberalism devalues, neglects, and/or undermines community, and community is a fundamental and irreplaceable ingredient in the good life for human beings." "ii) Liberalism undervalues political life-viewing political association as a merely instrumental good, it is blind to the fundamental importance of full participation in political community for the good life for human beings." / "iii) Liberalism fails to provide, or is incompatible with, an adequate account of the importance of certain types of obligations and commitments-those that are not chosen or explicitly undertaken through contracting or promising-such as familial obligations and obligations to support one's community or country." " "iv) Liberalism presupposes a defective conception of the self, failing to recognize that the self is 'embedded' in and partly constituted by communal commitments and values which are not objects of choice." " "v) Liberalism wrongly exalts justice as being 'the first virtue of social institutions, failing to see that, at best,justice is a remedial virtue, needed only in circumstances in which the higher virtue of community has broken down." BUCHANAN, Allen E. Assessing the communitarian critique of liberalism. Ethics, Chicago, v. 99, n. 4, p. 10, 1989.
Mas, além da inexistência de um conjunto teórico consistente, outra acusação feita ao comunitarismo é que lhe falta um projeto político alternativo. Isso é visto por alguns como uma limitação dele. Seria mesmo uma característica que lhe é própria e conforma seu escopo. Segundo alguns defensores do liberalismo, as críticas comunitárias não constituiriam um verdadeiro obstáculo e sim um desafio ao liberalismo, que pode incorporar algumas de suas críticas e seguir incólume. Para Amy Gutmann, por exemplo, "[o] fracasso dos críticos em minar o liberalismo não sugere que não haja valores comunitários, mas que eles sejam devidamente vistos como complementando ao invés de suplantando valores liberais básicos". ${ }^{24}$ Até mesmo comunitaristas como Walzer reconhecem suas limitações. De acordo com ele, as críticas comunitaristas estão fadadas à recorrência. De tempos em tempos, apareceriam para contestar o liberalismo. No entanto, em cada oportunidade, sairiam de um modo geral derrotadas, conseguindo apenas vitórias parciais, ao fazer incorporar algumas de suas ideias à tese liberal. ${ }^{25}$

Acredito que, colocado dessa forma, muito da importância do debate se perde. Vejo pelo menos três aspectos que devem ser considerados. Em primeiro lugar, a ideia da falta de um projeto político alternativo ao liberalismo parece ser sintomática. Com isso, quero dizer que essa percepção decorre das circunstâncias específicas em que se dá o debate. Como apontei acima, as críticas comunitárias ao liberalismo são lançadas no meio acadêmico norte-americano. Portanto, a discussão se dá a partir da tradição norte-americana. Considerando que a sociedade norte-americana é comumente descrita (inclusive pelos próprios comunitaristas) como sendo orientada por valores tipicamente liberais, o comunitarismo tem a tarefa de criticar o padrão vigente ou um modelo que já está de algum modo implementado. Por isso, a sensação de que o comunitarismo seria incapaz de propor um projeto político alternativo decorreria, a meu ver, de uma limitação prática. Não me parece ser razoável imaginar que, a partir de discussões teórico-filosóficas, a sociedade americana

${ }^{24}$ Tradução livre do original: “The critics' failure to undermine liberalism suggests not that there are no communitarian values but that they are properly viewed as supplementing rather than supplanting basic liberal values." GUTMANN, Amy. Communitarian critics of liberalism. Philosophy and public affairs, Malden, v. 14, n. 3, 1985, p. 320.

${ }^{25}$ WALZER, Michael. The communitarian critique of liberalism. Political theory, Thousand Oaks, v. 18, n. 1, 1990, p. 6. 
deixasse para trás a sua orientação liberal. O que seria possível, e é o que o comunitarismo às vezes consegue, é a incorporação de suas críticas ao modelo liberal.

Além disso, não me sinto convencido sequer de que o liberalismo tenha um projeto político concreto. $\mathrm{O}$ que há de concreto é a própria sociedade, mais especificamente, no caso do debate liberal-comunitário, a sociedade norte-americana. É somente a partir dessa sociedade que as críticas liberais e comunitárias fazem sentido. Quem sabe (essa é uma mera suposição), a sensação de que não haja um projeto político concreto pesasse para o lado oposto em outra sociedade, em uma sociedade em que a orientação fosse voltada a valores comunitários ou, ao menos, que esses valores predominassem em comparação aos liberais. Como forma de idealizar um cenário como esse, tomo a tradicional tipologia proposta por Esping-Andersen, sobre Estados de bem-estar. Nos países desenvolvidos, ele identifica três formas de manifestação: o "regime liberal", o "regime conservador-corporativo" e o "regime social-democrata". Nessa classificação, os Estados Unidos são normalmente enquadrados no regime liberal. Mas países como Suécia, Dinamarca, Noruega e Finlândia tendem ao regime social-democrata. ${ }^{26} \mathrm{Se}$ em alguma medida for possível afirmar que o regime social-democrata é mais próximo dos ideais comunitários do que dos liberais, talvez o debate se invertesse nesses países e a "recorrência" coubesse às teorias liberais.

O terceiro aspecto a considerar diz respeito à confusão inerente ao debate, que leva os contendedores a discutirem coisas diferentes. De acordo com Charles Taylor, a confusão ocorre porque no debate há duas questões absolutamente distintas em jogo, as questões ontológicas e as questões de defesa, e, não obstante sua diferença, “[...] tendem a ser abordadas em conjunto". ${ }^{27}$ As questões ontológicas seriam, de acordo com o autor, aquelas referentes ao antigo debate entre atomismo e holismo, no qual se busca definir os fatores que explicam a vida social. As questões de defesa, por outro lado, "[...] referem-se à posição moral ou à política que se adota". ${ }^{28}$ Nas questões de

${ }^{26}$ DRAIBE, Sônia M. Estado de bem-estar, desenvolvimento econômico e cidadania: algumas lições da literatura contemporânea. In: HOCHMAN, Gilberto; ARRETCHE, Marta; MARQUES, Eduardo (Org.). Políticas públicas no Brasil. Rio de Janeiro: Editora Fiocruz, 2007, p. 33-34.

27 TAYLOR, Charles. Argumentos filosóficos. São Paulo: Edições Loyola, 2000, p. 197.

${ }^{28}$ Ibidem, p. 198. defesa, as posições se organizariam em um mesmo feixe. Em uma extremidade, estariam as posições que dão prioridade aos direitos individuais e à liberdade (concepção individualista), enquanto na outra, estariam as posições que privilegiam a vida em comunidade e seus valores (concepção coletivista.).29

É possível verificar essa confusão a partir da análise de alguns elementos indicados anteriormente. Eu havia dito acima que a principal preocupação de Rawls é "[...] explicar [e demonstrar a prioridade das] liberdades e direitos básicos dos cidadãos como pessoas livres e iguais". ${ }^{30}$ Essa parece ser uma questão de defesa, já que dá destaque à prioridade da proteção do indivíduo em detrimento de outros valores. Analisando a teoria de justiça de Rawls, Sandel tem uma outra preocupação. Ele quer analisar algo que precede essa questão. Sandel busca investigar "[...] se os direitos podem ser identificados e justificados de uma forma que não pressupõe qualquer concepção particular de vida boa.". ${ }^{31}$ Sandel, portanto, examina os pressupostos da teoria de Rawls (notadamente a qualidade dos sujeitos desinteressados da posição original). Trata-se, portanto, de uma indagação ontológica. Enquanto tal, as respostas a que chega não correspondem à defesa de nenhum tipo de posição. O que a tese ontológica faz é simplesmente "[...] estruturar o campo de possibilidades de uma maneira mais clara". ${ }^{32}$ Com base nas proposições de Sandel, Taylor diz, por exemplo, que "[...] poderíamos alegar que tanto eus (relativamente) libertos como eu [sic] (relativamente) situado são possibilidades, tal como seriam sociedades (relativamente) atomistas e sociedades (relativamente) holistas, mas que as combinações viáveis desses dois níveis são restritas". ${ }^{33}$ Isso porque "[...] seria difícil combinar uma sociedade altamente coletivista com uma identidade liberta, assim como uma forma de vida altamente individualista seria impossível onde os selves fossem estritamente situados". ${ }^{34}$ No entanto, liberais

${ }^{29}$ TAYLOR, Charles. Argumentos filosóficos. São Paulo: Edições Loyola, 2000.

${ }^{30}$ RAWLS, John. Uma teoria da justiça. São Paulo: M. Fontes, 2000, p. 14.

${ }^{31}$ Tradução livre do original: "[...] is not whether rights are important but whether rights can be identified and justified in a way that does not presuppose any particular conception of good life." SANDEL, Michael. Liberalism and the limits of justice. 2. ed. Cambridge: Cambridge University Press, 1998, p. x.

${ }^{32}$ Ibidem, p. 199.

${ }^{33}$ Ibidem.

${ }^{34}$ Ibidem. 
como Buchanan rebatem as críticas de Sandel dizendo que o papel do Estado não deve ser impor aos cidadãos uma concepção substantiva de boa vida, mas tão somente proteger os seus direitos básicos. ${ }^{35}$ Está instaurada a confusão, já que definir a posição política do Estado entre a proteção de direitos individuais ou valores comunitários é uma questão de defesa. Embora a relação entre questões ontológicas e de defesa não seja totalmente independente (já que a identificação das possibilidades terá impacto na sua escolha posterior), uma não pode ser tomada pela outra. Nos comentários que seguem, pretendo não incorrer nessa mesma confusão.

\subsection{Analisando os argumentos}

Não me parece razoável pretender inferir questionamentos ontológicos dos argumentos elaborados pelas três associações. A exposição por elas feita não contém elementos suficientes para tanto. Por isso, limito minha análise a questões de defesa. O que faço a seguir é precisamente uma tentativa de reconstrução das teses que as associações desenvolveram na ADI no 3.059/RS, de modo a tornar explícitos os fundamentos filosóficos que nortearam seus argumentos ou que, pelo menos, sejam com eles compatíveis. Começo pela ABES e ASSESPRO Nacional.

Acredito que à tese formulada por essas duas associações pode ser associada uma concepção de justiça liberal, e por dois motivos. Por um lado, a construção do argumento sobre a violação do princípio da impessoalidade é feita como defesa de um direito básico: a igualdade. Esta, juntamente com a liberdade, é entendida como um dos principais e mais básicos direitos dos cidadãos (que, nesse caso, é estendido às sociedades empresárias). Consoante à tese liberal, o papel do Estado é proteger esse direito básico, sem considerações de outra natureza. O princípio da impessoalidade seria simplesmente uma derivação lógica do princípio da igualdade, cuja aplicação se dá nas relações do Estado com seus cidadãos. O conteúdo do princípio da impessoalidade obedece ao seguinte raciocínio: se os cidadãos devem ser tratados igualmente, o Estado não pode privilegiar qualquer deles, devendo, por isso, agir de maneira impessoal. Para as associações,

\footnotetext{
35 Tradução livre do original: “[...] the proper role of the state is to protect basic individual liberties, not to make its citizens virtuous or to impose upon them any particular or substantive conception of the good life." BUCHANAN, Allen E. Assessing the communitarian critique of liberalism. Ethics, Chicago, v. 99, n. 4,1989 , p. 854.
}

ao estabelecer uma preferência pelo software livre, o Estado do Rio Grande do Sul não agiu dessa maneira, tratando os produtores de software proprietário de maneira desigual. Diante disso, fazem um apelo ao STF para que, sem quaisquer outras considerações, defenda seu direito à igualdade.

Por outro lado, há outra leitura do argumento que lhe confere o caráter liberal. De acordo com Taylor, há uma família de teorias liberais - a que chama de procedimentalista - que "[...] vê a sociedade como uma associação de indivíduos, cada um dos quais [tendo] uma concepção de vida boa ou válida e, correspondentemente, um plano de vida. A função da sociedade deve ser facilitar esse plano de vida o máximo possível e seguir algum princípio de igualdade". ${ }^{36}$ Mas é vedado ao Estado impor aos demais cidadãos qualquer concepção de boa vida específica. Se assim o fizesse, e se alguns não compartilhassem dessa concepção particular de boa vida, teria tratado uma parcela de seus cidadãos, quanto a esse aspecto, desigualmente. A tarefa da sociedade seria, portanto, estabelecer critérios de decisão para determinar a escolha por certos bens, sem que essa escolha implique na adoção de uma dada concepção de vida. ${ }^{37} \mathrm{O}$ objetivo é criar um conjunto de regras que permitam conferir tratamento igualitário entre os concorrentes até que se faça a escolha pelo bem. Daí, porque a definição desses critérios constituiria um tipo de teoria da justiça procedimental.

No argumento da ABES e da ASSESPRO Nacional essa ideia parece estar latente. Em determinado momento, as associações fazem menção a um instrumento eleito pela Constituição para garantir efetividade ao princípio da impessoalidade. Esse instrumento seria a licitação. Ora, a licitação nada mais é do que um procedimento criado para determinar a escolha daqueles que firmarão contratos com o Estado. As associações depositam sua confiança na fiel observância desse procedimento. A escolha por um dos concorrentes seria justa, na medida em que o procedimento fosse efetivamente seguido. O problema com a lei gaúcha, segundo a ABES e a ASSESPRO Nacional, é que o próprio procedimento foi alterado e, da forma como ficou, não é mais possível afirmar que o resultado será justo. Há, aqui, duas questões. De um lado,

\footnotetext{
36 TAYLOR, Charles. Argumentos filosóficos. São Paulo: Edições Loyola, 2000, p. 202.

${ }^{37}$ Ibidem, p. 202-203.
} 
parece claro que as associações defendem uma teoria de justiça (liberal) procedimental. Do outro, levam a entender que o procedimento adotado pelo Estado do Rio Grande do Sul não garante um resultado justo. Quanto a essa segunda questão, é pertinente a distinção feita por Rawls entre três espécies de justiça procedimental: a perfeita, a imperfeita e a pura.

Para Rawls, a justiça procedimental perfeita “[...] estabelece um critério independente para uma divisão justa, um critério definido em separado e antes de o processo acontecer”, de tal maneira que “[...] é possível criar um procedimento que com certeza trará o resultado desejado". ${ }^{38}$ Para ilustrar esse procedimento, Rawls cita o exemplo de homens dividindo um bolo, sendo que aquele que o parte será o último a receber sua fatia. Se for de seu interesse receber o maior pedaço possível, ele fatiará o bolo em pedaços iguais. Na justiça procedimental imperfeita, há “[...] um critério independente para produzir o resultado correto, [mas] não há processo factível que com certeza leve a ele". ${ }^{39} \mathrm{O}$ exemplo, nesse caso, é o da justiça criminal. O processo penal busca estabelecer a verdade, a partir de um procedimento que organiza a forma de elaborar provas. A intenção é condenar os culpados e absolver os inocentes; entretanto, o procedimento não é capaz de garantir que esse será o resultado efetivamente alcançado. A terceira espécie seria a justiça procedimental pura. Nela,

[...] não há critério independente para o resultado correto: em vez disso, existe um procedimento correto ou justo de modo que o resultado será também correto ou justo, qualquer que seja ele, contanto que o procedimento tenha sido corretamente aplicado ${ }^{40}$

Como exemplo, Rawls menciona o jogo: "Se um certo número de pessoas se engaja em uma série de apostas justas, a distribuição do dinheiro após a última aposta é justa, ou pelo menos não injusta, qualquer que seja essa distribuição"*1

Afirmar a que tipo de justiça procedimental ABES e ASSESPRO Nacional se referem é exercício de especulação, já que não há elementos evidentes em sua manifestação que auxiliem nessa empreitada. De qualquer forma,

\footnotetext{
${ }^{38}$ RAWLS, John. Uma teoria da justiça. São Paulo: M. Fontes, 2000, p. 91.

${ }^{39}$ Ibidem, p. 92.

${ }^{40}$ Ibidem, p. 92

${ }^{41}$ Ibidem.
}

é possível fazer algumas suposições. As duas associações parecem depositar plena confiança na licitação. Ela é o legítimo instrumento - eleito pela Constituição - que garante o respeito ao princípio da impessoalidade (e, por conseguinte, da igualdade). Nesse sentido, a ideia subjacente à licitação constituiria um tipo de justiça procedimental pura. Toda vez que a licitação for conduzida de acordo com o que estabelece seu procedimento, o resultado, qualquer que seja ele, será justo. O problema da lei gaúcha é justamente a maneira como interferiu no procedimento e, consequentemente, em seu resultado. Ao prever tratamento desigual entre produtores de software proprietário e produtores de software livre, o procedimento foi de tal modo desvirtuado que, necessariamente, todo resultado que dele se origine será injusto.

Passo, agora, a examinar as teses do IBDI. Como disse anteriormente, a resposta à violação do princípio da impessoalidade segue dois caminhos. Ao mesmo tempo em que defende a preferência estipulada pela Lei $n^{\circ}$ $11.871 / 2002$, o IBDI atribui a responsabilidade pela violação daquele princípio à utilização do software proprietário. Na primeira hipótese, o argumento do instituto não é mais nem menos liberal do que o das outras associações. O que faz é desqualificar a preferência pelo software livre como forma de discriminação. Tudo começa quando sustenta que a diferença entre software proprietário e software livre reside tão-somente na forma de licenciamento do produto. No caso do software proprietário, o detentor dos direitos de propriedade intelectual cede o produto a terceiro (o Estado, por exemplo), cobrando por isso uma taxa. Os termos do licenciamento do software livre são sensivelmente distintos. Além de, normalmente, não se cobrarem taxas pela cessão do software, o licenciante tem direito a acessar o código-fonte (que é o conjunto de informações que descreve todo o funcionamento do software), bem como alterar o produto. Assim, não se trataria de produtos diferentes, mas de produtos similares licenciados de modo diferente.

O argumento prossegue, e toma feição liberal, quando se afirma que o licenciamento do software é escolha do detentor dos direitos de propriedade intelectual. Caberia aos próprios concorrentes decidir como querem comercializar seus produtos. É a liberdade, outro direito básico dos cidadãos, o fundamento de defesa. Com isso, o tratamento concedido pelo Estado aos concorrentes volta a ser igualitário e a alteração promovida pela lei gaú- 
cha conserva, para a licitação, o atributo de mecanismo de justiça procedimental pura. O licenciamento se torna apenas mais um dentre os diversos fatores a serem examinados no procedimento licitatório.

Mas essa é apenas uma das formas possíveis de se entender a defesa da preferência pelo software livre. Acredito que possa haver outra, de viés comunitário. Para abordá-la, quero fazer algumas considerações prévias sobre o outro argumento do IBDI. Trata-se da acusação de que a utilização do software proprietário leva à violação do princípio da impessoalidade. Esse argumento se baseia na ideia de monopólio, que decorreria da dinâmica imposta pelo licenciamento proprietário. Em virtude de o usuário ser impedido de ter acesso às informações que explicam o funcionamento do programa de computador e, também por não poder fazer qualquer tipo de modificação no produto, o licenciamento proprietário criaria uma situação de dependência tecnológica do licenciado (o Estado, por exemplo) em relação ao licenciante. Sempre que aquele precisar fazer algo que não seja permitido pelo licenciamento, terá necessariamente que contratar o detentor dos direitos de propriedade intelectual para realizar a tarefa. Daí, porque o monopólio.

Analisando algumas das teorias de justiça comunitárias disponíveis, imaginei que pudesse ser cabível associar esse argumento às ideias de Michael Walzer. Walzer elabora uma teoria da justiça que pretende compatibilizar igualdade e pluralismo. ${ }^{42}$ Para isso, é fundamental a noção de esferas da justiça. Segundo o autor, há uma diversidade de bens disponíveis na sociedade: cidadania, poder, honra, segurança, amor, riqueza, conhecimento etc. E cada um desses bens segue um critério específico de distribuição social. Forma-se, assim, o conceito de esferas de justiça. A distribuição será justa sempre que obedecer àqueles critérios que são adequados para cada bem; será injusta, por outro lado, quando a distribuição de um bem determinar a distribuição de outro bem. Um exemplo pode ajudar a esclarecer essas ideias. Enquanto poder e riqueza forem distribuídos de acordo com os critérios que lhe são próprios, a distribuição será justa. No entanto, quando a distribuição do poder decorrer da distribuição da riqueza, então a distribuição do poder será injusta. Cada esfera deve funcionar em condição de autonomia

${ }^{42}$ WALZER, Michael. Spheres of justice: a defense of pluralism and equality. Nova York: Basic Books, 1983. em relação às outras, evitando que a distribuição em uma interfira na distribuição feita em outra.

Aplicando essas ideias ao argumento do IBDI, será possível dizer que o monopólio gerado pelo licenciamento do software proprietário afeta a distribuição de algum outro bem? Talvez, mas desde que se compreenda o lugar do monopólio na teoria de Walzer. Isso porque, ao invés do que normalmente se poderia esperar, o autor não acredita que o objetivo de sua teoria seja ilidir a prática de monopólios. Pelo contrário, sua teoria pode, inclusive, justificá-los, desde que circunscritos a esferas determinadas. Para Walzer, os monopólios não são intrinsecamente ruins. O mal a ser evitado é a dominação. O termo dominação é utilizado por Walzer para descrever a prevalência que determinados bens exercem sobre outros. Logo no início da obra, o próprio autor fornece um conceito: "Eu chamo um bem dominante se os indivíduos que o tem, porque eles o tem, podem comandar uma grande variedade de outros bens". ${ }^{43}$ Assim, quando um bem é dominante, ele exerce influência sobre várias esferas de distribuição, determinando seus valores e condicionando a ele a importância dos outros bens. Ao invés de dominação, é necessário que se garanta a autonomia dos bens. Portanto, os monopólios devem ser combatidos quando englobam bens dominantes.

O problema para o argumento do IBDI é, desse modo, identificar as respectivas esferas de justiça e conferir se um bem é dominante em relação ao outro. Começo destacando os elementos. Em primeiro lugar, suponho que a propriedade intelectual pode ser considerada um bem. Menciono a propriedade intelectual por ser ela a fonte do direito sobre o software; é a partir do direito de propriedade intelectual que os concorrentes licenciam seus produtos de maneira livre ou não. Diante disso, resta saber se a propriedade intelectual (e, por consequência, o licenciamento do software) influi na distribuição de algum outro bem. O IBDI sustenta que o software proprietário gera monopólio, porque apenas ao detentor dos direitos de propriedade intelectual é dada a possibilidade de, por exemplo, efetuar serviços de modificação do programa de computador. Nesse ponto, porém, não me

\footnotetext{
${ }^{43}$ Tradução livre do original: "I call a good dominant if the individuals who have it, because they have it, can command a wide range of other goods." WALZER, Michael. Spheres of justice: a defense of pluralism and equality. Nova York: Basic Books, 1983. p. 1.
} 
parece que o licenciamento interfira na distribuição de um bem diferente. A propriedade intelectual condiciona a forma de negociação de um produto, seja sua venda, sejam os serviços correlatos. Dessa maneira, o monopólio se circunscreve a uma mesma esfera de justiça.

O resultado talvez fosse diferente se pudesse acrescentar mais um elemento a essa situação. É que a propriedade intelectual pode interferir na distribuição de outro bem: o conhecimento. Ao impedir que o licenciado tenha acesso ao código-fonte do programa de computador, o licenciamento proprietário condiciona a distribuição do conhecimento sobre esse tipo de produto e seu funcionamento. Essa ideia reflete, inclusive, a discussão a respeito do equilíbrio entre proteção (dos criadores) e acesso (à informação), tema frequente entre aqueles que discutem os fundamentos da propriedade intelectual.

\section{Conclusão}

O exercício que realizei nas últimas páginas suscita sérias dúvidas. Não é de todo evidente o fato de que existam, em meio a argumentos lançados em um processo judicial, concepções de justiça latentes, subentendidas. Nos documentos elaborados para um processo, a preocupação imediata é com o êxito da demanda. O objetivo é persuadir o julgador, de modo a não lhe dar outra opção senão decidir no mesmo sentido de suas arguições. Algo bem distinto ocorre nas discussões sobre concepções de justiça. Por se tratar de preocupação eminentemente filosófica, a intenção precípua não é convencer, mas fazer pensar. É claro que todo aquele que elabora uma teoria o faz contando que convencerá alguns. No entanto, ainda que não consiga convencer ninguém, nem por isso sua tarefa terá sido mal sucedida.

De qualquer forma, uma circunstância milita em meu favor. Supondo que eu tenha sido capaz de correlacionar coerentemente concepções de justiça aos argumentos das associações, é possível afirmar que o debate norte-americano tem algo a contribuir para discussões semelhantes no Brasil. Há muito a fazer, é claro. Todo o arcabouço teórico exposto alhures é pensado a partir da tradição norte-americana. Tanto questões ontológicas como questões de defesa devem ser reanalisadas e compatibilizadas com nossa própria realidade social. É preciso identificar as possibilidades de arranjo justo da nossa sociedade e pensar o papel que o Estado deve desempenhar. Esse, portanto, foi apenas um primeiro passo.

\section{Referências}

BRASIL. Supremo Tribunal Federal. ADI no 3.059/RS.

BRASIL. Supremo Tribunal Federal. ADI $n^{\circ}$ 3.059/RS. Mimeo. Disponível em: <www.stf.jus.br>.

BUCHANAN, Allen E. Assessing the communitarian critique of liberalism. Ethics. Chicago, v. 99, n. 4, 1989.

DRAIBE, Sônia M. Estado de bem-estar, desenvolvimento econômico e cidadania: algumas lições da literatura contemporânea. In: HOCHMAN, Gilberto; ARRETCHE, Marta; MARQUES, Eduardo (Org.). Políticas públicas no Brasil. Rio de Janeiro: Editora Fiocruz, 2007.

GUTMANN, Amy. Communitarian critics of liberalism. Philosophy and Public Affairs, Malden, v. 14, n. 3, 1985.

RAWLS, John. Uma teoria da justiça. São Paulo: M. Fontes, 2000.

RIO GRANDE DO SUL. Assembleia Legislativa. Projeto de Lei $n^{\circ}$ 06/2002. Mimeo.

SANDEL, Michael. Liberalism and the limits of justice. 2. ed. Cambridge: Cambridge University Press, 1998.

TAYLOR, Charles. Argumentos filosóficos. São Paulo: Edições Loyola, 2000.

WALZER, Michael. Spheres of justice: a defense of pluralism and equality. Nova York: Basic Books, 1983.

WALZER, Michael. The communitarian critique of liberalism. Political theory, Thousand Oaks, v. 18, n. 1, 1990.

WITTGENSTEIN, Ludwig. The nature of philosophy. In: KENNY, Anthony (Ed.). The Wittgenstein reader. 2. ed. Oxford: Blackwell Publishing Ltd., 2006. 